Portland State University

PDXScholar

Environmental Science and Management

Faculty Publications and Presentations

$5-1-2017$

\title{
Gas Transfer Velocities in Small Forested Ponds
}

Meredith A. Holgerson

Portland State University

Emily R. Farr

Yale University

Peter A. Raymond

Yale University

Follow this and additional works at: https://pdxscholar.library.pdx.edu/esm_fac

Part of the Environmental Sciences Commons

Let us know how access to this document benefits you.

Citation Details

Holgerson, Meredith A.; Farr, Emily R.; and Raymond, Peter A., "Gas Transfer Velocities in Small Forested Ponds" (2017). Environmental Science and Management Faculty Publications and Presentations. 204. https://pdxscholar.library.pdx.edu/esm_fac/204

This Post-Print is brought to you for free and open access. It has been accepted for inclusion in Environmental Science and Management Faculty Publications and Presentations by an authorized administrator of PDXScholar. Please contact us if we can make this document more accessible: pdxscholar@pdx.edu. 
Title: $\quad$ Gas transfer velocities in small forested ponds

Authors: $\quad$ Meredith A. Holgerson ${ }^{1,2^{*}}$, Emily R. Farr ${ }^{1}$, and Peter A. Raymond ${ }^{1}$

Institutions: ${ }^{1}$ School of Forestry and Environmental Studies, Yale University, New Haven, CT 06511

${ }^{2}$ Present address: Department of Environmental Science and Management, Portland State University, Portland, OR 97201

*Corresponding author: Meredith A. Holgerson (meredith.holgerson@ gmail.com)

\section{Key Points:}

- Gas exchange rates in small ponds are low, but variable across space and time

- With increasing lake size, gas exchange rates increase and become more variable

- Uncertainty in gas exchange rates undermine estimates of ecosystem metabolism and gas emissions in inland waters

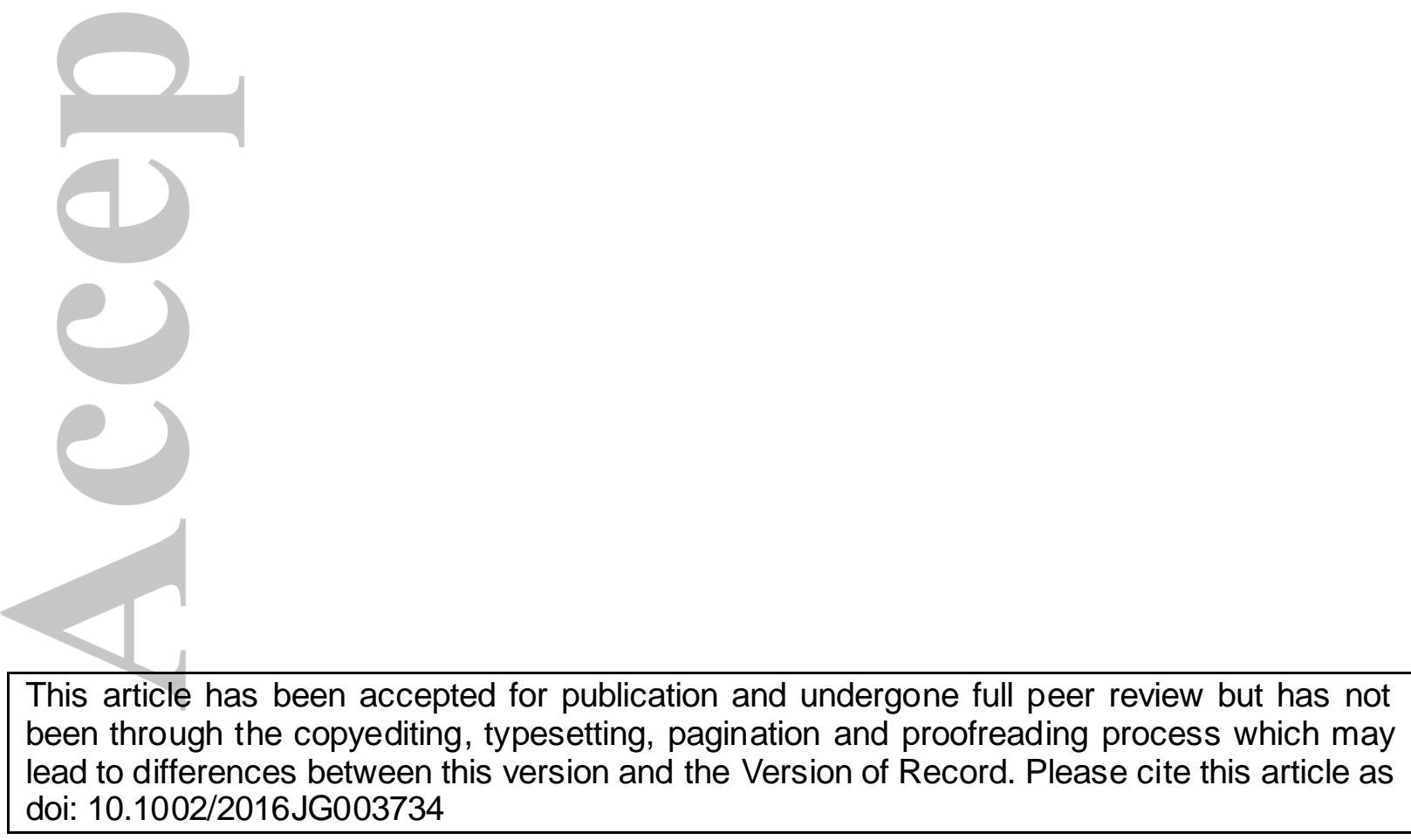




\section{Abstract}

Inland waters actively exchange gases with the atmosphere, and the gas exchange rate informs system biogeochemistry, ecology, and global carbon bud gets. Gas exchange in medium- to large-sized lakes is largely regulated by wind; yet less is known about processes regulating gas transfer in small ponds where wind speeds are low. In this study, we determined the gas transfer velocity, $k_{600}$, in four small $\left(<250 \mathrm{~m}^{2}\right)$ ponds using a propane $\left(\mathrm{C}_{3} \mathrm{H}_{8}\right)$ gas injection. When estimated across 12 -hour periods, the average $k_{600}$ ranged from 0.19 to $0.72 \mathrm{~m} \mathrm{~d}^{-1}$ across the ponds. We also estimated $k_{600}$ at two- to three-hour intervals during the day and evaluated the relationship with environmental conditions. The average daytime $k_{600}$ ranged from 0.33 to $1.83 \mathrm{~m} \mathrm{~d}^{-1}$ across the ponds and was best predicted by wind speed and air or air-water temperature, however the explanatory power was weak $\left(\mathrm{R}^{2}<0.27\right)$ with high variability within and among ponds. To compare our results to larger water bodies, we compiled direct measurements of $k_{600}$ from 67 ponds and lakes worldwide. Our $k_{600}$ estimates were within the range of estimates for other small ponds, and variability in $k_{600}$ increased with lake size. However, the majority of studies were conducted on medium-sized lakes $\left(0.01\right.$ to $\left.1 \mathrm{~km}^{2}\right)$, leaving small ponds and large lakes understudied. Overall, this study adds four small ponds to the existing body of research on gas transfer velocities from inland waters and highlights uncertainty in $k_{600}$, with implications for calculating metabolism and carbon emissions in inland waters. 


\section{Introduction}

Inland waters actively exchange gases with the atmosphere, with important consequences for ecosystem dynamics such as carbon emissions [Schilder et al., 2013; Seekell et al., 2014], oxygen availability [Melack and Fisher, 1983; Holgerson et al., 2016], and food web structure [Schindler et al., 1997; Devlin et al., 2015]. For instance, air-water gas exchange rates influence the extent to which greenhouse gases, such as carbon dioxide $\left(\mathrm{CO}_{2}\right)$, methane $\left(\mathrm{CH}_{4}\right)$, and nitrous oxide $\left(\mathrm{N}_{2} \mathrm{O}\right)$, are released by inland waters. The gas transfer velocity, $k$, partly controls the exchange rate and is largely driven by turbulence at the air-water interface [MacIntyre et al., 1995]. In large water bodies, wind speed often drives turbulence because it creates surface waves and shear stress that increase $k$ [MacIntyre et al., 1995]. As such, wind speed is often used to model $k$ in lakes [Cole and Caraco, 1998] and the ocean [Wanninkhof, 1992]. However, the relationship between wind speed and $k$ typically breaks down under low wind conditions, characteristic of smaller and more sheltered waters [Clark et al., 1995; Cole and Caraco, 1998].

Considering that over $90 \%$ of lakes and ponds world wide are less than one ha in size [Downing et al., 2006; Verpoorter et al., 2014] and that small ponds play a disproportionately large role in greenhouse gas emissions [Holgerson and Raymond, 2016], it is critical to determine their $k$. Furthermore, because directly measuring $k$ is time intensive, it is important to evaluate if any environmental parameters can be used to predict $k$. Other than wind, environmental factors that influence turbulence and can be readily measured or estimated include surfactants, rainfall, and convection. Surfactants are formed by hydrophobic organic compounds, and they reduce wind stress at the surface, can obstruct molecular diffusion, and ultimately decrease gas transfer [MacIntyre et al., 1995]. Raindrops physically increase turbulence at the air-water interface and increase gas exchange [Ho et al., 1997]. Convection can influence $k$ through seasonal and diurnal changes in air-water temperature, particularly in 
small water bodies [Matthews et al., 2003; Poindexter and Variano, 2013]. For instance, convection from cooling surface waters can increase gas transfer velocities by increasing turbulence in the surface mixing layer [MacIntyre et al., 2010; Holgerson et al., 2016]. The importance of convective cooling may be greater in small systems because they exhibit more extreme diurnal temperature changes than larger lakes, which increases sensible heat flux and convective turbulence [Woolway et al., 2016]. The relative importance of convection versus wind on $k$ may be mediated by lake surface area, with wind dominating in larger systems and convection being more important in smaller, more sheltered lakes and ponds [Read et al., 2012].

There are multiple approaches for estimating $k$, including whole- lake gas tracers, floating chambers, directly measuring turbulence, meteorological techniques (e.g., eddy flux), and modeling techniques, all of which have limitations [Matthews et al., 2003; Zappa et al., 2007; Cole et al., 2010]. Whole-lake tracers use gases such as sulfur hexafluoride $\left(\mathrm{SF}_{6}\right)$, helium $\left({ }^{3} \mathrm{He}\right)$, or propane $\left(\mathrm{C}_{3} \mathrm{H}_{8}\right)$, which are added to a water body and the gas los s over time is used to estimate $k$ [e.g., Wanninkhof et al., 1985; Clark et al., 1995; Frost and UpstillGoddard,2002; Cole et al., 2010; Jin et al., 2012]. However, this approach can be timeintensive and costly, particularly for large water bodies. Floating chambers are easy to deploy but they create microenvironments within the chamber that exclude effects of wind and rainfall, generate artificial turbulence, change the atmospheric pressure, and alter the airwater concentration gradient [Matthews et al., 2003; Vachon et al., 2010]. Additionally, there is often high spatial and temporal variability that may not be captured by chambers that are only deployed for a short time [Schilder et al., 2013; Vachon and Prairie, 2013]. Flux chambers can also grossly overestimate $k$ in low-turbulence environments [Vachon et al., 2010], characteristic of smaller water bodies. Directly measuring turbulence and eddy flux 
techniques work well, but require expensive equipment, and are usually employed only in larger water bodies with adequate fetch [e.g., Jonsson et al., 2008].

Models offer the benefit that $k$ can be estimated for water bodies that were never sampled, thus saving time, money, and allowing for gas exchange estimates to be extrapolated to the regional or global scale. Predictive models were originally based entirely on wind speed [Wanninkhof, 1992; Clark et al., 1995; Cole and Caraco, 1998] and more recently, models have included components for other variables such as lake area [Vachon and Prairie, 2013], wave breaking [Soloviev et al., 2007; Winslow et al., 2016], and buoyancy flux to capture convection [MacIntyre et al., 2010; Read et al., 2012]. For instance, the surface renewal model takes into account turbulence generated from both wind and heat loss, which creates instability at the air-water interface, particularly when the water becomes warmer than the air [MacIntyre et al., 1995]. Numerous models are now available for estimating $k$, with varying data requirements [Winslow et al., 2016]. While these models are useful, they first require field sampling and validation across diverse water bodies.

Field studies have shown that the wind speed-gas exchange relationship breaks down under low wind speeds $\left(<3 \mathrm{~m} \mathrm{~s}^{-1}\right)$ [Clark et al., 1995; Cole and Caraco, 1998] and models predict convection will dominate in these low-wind and oftentimes smaller water bodies [Read et al., 2012]. While some field studies have estimated $k$ in small lakes, we are not aware of any study conducted in ponds smaller than 3,000 $\mathrm{m}^{2}$ [Cole et al., 2010; Schilder et al., 2013]. Considering that there could be as many as 3 billion ponds between 100 and 1,000 $\mathrm{m}^{2}$ globally [Downing, 2010] and that small ponds are hotspots for carbon emissions [Holgerson and Raymond, 2016], it is critical to determine their $k$.

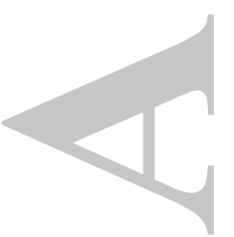


Our study aims to fill this research gap by using whole-pond gas tracer studies to measure $k$ in four small $\left(<250 \mathrm{~m}^{2}\right)$, low-wind ponds. We then compared $k$ to environmental parameters including wind speed, rain, light, and air and pond temperatures. We expected that pond cooling, indicative of convection, would be more important than wind in predicting $k$. Lastly, we compiled data from 67 ponds and lakes worldwide where $k$ was directly measured in order to compare values and variability across a spectrum of lake sizes. We expected that $k$ would increase with lake size, and were curious about variability across lake size classes.

\section{Methods}

2.1. Study Sites

We evaluated the gas transfer velocity, $k$, in four small, temporary ponds in YaleMyers forest in northeastern Connecticut during May and June 2013. The ponds ranged in surface area from 181 to $225 \mathrm{~m}^{2}$ and in mean depth from 31 to $56 \mathrm{~cm}$ (Table 1). The four ponds, Brookside, $\mathrm{CH}, \mathrm{RH}$, and Westford, were chosen for their closed basins with minimal emergent vegetation. The closed basin prevents the gas tracer from being diluted by inflow or escaping with outflow. The lack of emergent vegetation ensured that plant matter was not an important factor in regulating $k$ [Poindexter and Variano, 2013]. During its sampling period, $\mathrm{RH}$ had ferns in about $20 \%$ of the basin along the edge and about 10 trees in the sides of the basin because it was sampled after a period of rain and therefore had higher water levels. All four ponds are heavily sheltered by the surrounding forest and thus have negligible fetch. Westford and $\mathrm{CH}$ are located within the forest directly beside roads, and Brookside and $\mathrm{RH}$ are both surrounded entirely by forest approximately $0.5 \mathrm{~km}$ from a road.

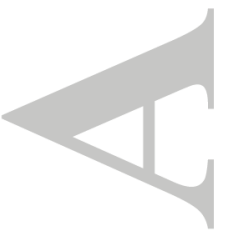




\subsection{Environmental Conditions}

To monitor environmental conditions at each pond, we used a datalogger (Campbell Scientific CR300) to log measurements of wind speed $\left(\mathrm{m} \mathrm{s}^{-1}\right)$ and wind direction (degrees), air and water temperature $\left({ }^{\circ} \mathrm{C}\right), \operatorname{PAR}$ (photosynthetically active radiation) ( $\mu \mathrm{mol} \mathrm{s} \mathrm{s}^{-2}$ ), and rainfall $(\mathrm{mm})$ at 15-minute intervals in each pond. We positioned the anemometer (height above water level: Westford $75 \mathrm{~cm}$, Brookside $77 \mathrm{~cm}, \mathrm{CH} 50 \mathrm{~cm}, \mathrm{RH} 35 \mathrm{~cm}$ ), temperature probes, and photometer (LI-190 Quantum Sensor, LI-COR) on a stake at the deepest point of each pond. A tipping-bucket rain gauge located on a separate stake in the least canopycovered region of each basin measured precipitation. We asses sed pond bathymetry by measuring depth every meter along five transects per pond. We assumed ponds had elliptical basins to estimate surface area and used depth measurements to estimate pond volume.

\subsection{Gas Sampling}

We injected the ponds with propane because it is an inert gas with negligible background concentrations in the air and water. On the first day of sampling, we used an airstone to bubble propane into eight 18.9-L carboys filled with pond water for 10 minutes each at 13 psi. We added $3 \mathrm{ml}$ of rhodamine to each carboy as a tracer to determine when the pond had completely mixed. The carboys were well mixed and we sampled each carboy to determine initial propane concentrations. We then poured the carboy mixtures throughout the entire pond basin, and walked through the pond to help with mixing. We used a handheld datalogger (Turner Designs DataBank ${ }^{\mathrm{TM}}$ ) to measure rhodamine concentrations twice a day for the first two days to verify that the propane concentration mixed throughout the pond.

We took our first measurements six hours after the propane addition, which is when rhodamine concentrations indicated that the propane had mixed evenly throughout the pond basin. We measured propane concentrations from surface waters $(\sim 13 \mathrm{~cm}$ below the surface $)$ at the deepest point of each pond using a peristaltic pump (Cole-Parmer Masterflex E/S ${ }^{\mathrm{TM}}$ 
portable sampler $115 \mathrm{VAC})$. We took occasional samples manually without the pump as a result of instrument malfunction. We sampled every 2 hours for the first 24 hours, then every 3 hours for the remaining 72 hours, excluding the interval between 20:00 h and 08:00 h due to daylight constraints. We measured propane concentration using a headspace equilibration technique [Raymond et al., 1997]. Briefly, we filled a beaker with water from the peristaltic pump and allowed it to flush for several volumes. We took three replicate $40-\mathrm{ml}$ water samples from the beaker using an airtight 60 - $\mathrm{ml}$ syringe, then immediately drew in $20 \mathrm{ml}$ of ambient air. We shook the syringe vigorously for 2 minutes in order to equilibrate the air and water phases. Samples of the headspace were then stored and transported to the laboratory in airtight, evacuated glass vials (Labco Limited, United Kingdom).

We measured propane concentrations using a gas chromatograph (GC) (SRI 310C) with a $3.5-\mathrm{mm}$ column. The GC temperature settings were as follows: detector temperature to $150^{\circ} \mathrm{C}$ and oven temperature to $100^{\circ} \mathrm{C}$, resulting in a propane retention time of $\sim 4.08$ minutes. We injected all propane samples in 1-ml quantities with a 1-ml syringe. We also ran propane samples taken from the eight carboys for each pond on the GC with equivale nt initial temperature settings but injected 0.5 - $\mathrm{ml}$ volumes. PeakSimple 4.09 software measured the propane peak area in each sample, which we converted to concentration $\left(\mathrm{ppm}_{\mathrm{v}}\right)$ using propane calibration curves. In order to obtain pond propane concentrations, we multiplied measured propane concentrations by $3 / 2$ to correct for the dilution with ambient air during headspace equilibration. 


\subsection{Estimating Gas Transfer Velocity}

Gas transfer between aquatic surfaces and the atmosphere is described by the equation:

$$
F=k\left(C_{\text {sur }}-C_{e q}\right)
$$

where $F$ is the gas flux $\left(\mathrm{mmol} \mathrm{m} \mathrm{d}^{-2} \mathrm{~d}^{-1}\right), k$ is the gas transfer velocity $\left(\mathrm{m} \mathrm{d}^{-1}\right), C_{\text {sur }}$ is the gas concentration in the surface water, and $C_{e q}$ is the gas concentration when in equilibrium with the atmosphere. For the propane additions, we directly measured $F, C_{s u r}$, and $C_{e q}$, allowing for the derivation of $k$.

To derive $k$, we first used a Grubbs outlier test to discount any erroneous propane concentrations that resulted from sampling error. We then converted the average propane concentrations $\left(\mathrm{ppm}_{\mathrm{v}}\right)$ of the triplicates at each time point to units of $\mathrm{mol} \mathrm{L} \mathrm{L}^{-1}$ using Henry's law constants [Mohebbi et al., 2012; Sander, 2015]. We calculated $k$ across two different time scales: (1) for each 12-hour sampling interval and (2) for each 2- or 3-hour sampling period during the day. Longer time scales may more accurately reflect the overall ecosystem gas transfer velocity [Wanninkhof et al., 1987], while shorter time periods better allow for comparisons to be made to environmental conditions.

To calculate $k\left(\mathrm{~m} \mathrm{~d}^{-1}\right)$, we used the following equation [Wanninkhof et al., 1987]:

$$
k=\frac{h}{\Delta t} \ln \frac{C_{i}-C_{o}}{C_{f}-C_{o}}
$$

where $h$ is the average depth of the pond, $\Delta t$ is the time interval, $C_{i}$ and $C_{f}$ are the initial and final propane concentrations in the pond, respectively, and $C_{o}$ is the background concentration of propane in the water. We computed a verage pond depth, $h$, by taking the mean of the measured depths for each square meter measured in each pond. Since $\mathrm{C}_{\mathrm{o}}$ of propane is negligible in this experiment, (Eq. 2) becomes:

$$
k=\frac{h}{\Delta t} \ln \frac{C_{i}}{C_{f}}
$$


Because we measured propane concentrations multiple times during the day, to estimate $k$ for 12-hour daytime periods, we performed a linear regression to determine the slope of concentration change over time for each 12-hour daytime interval of sampling, and this slope replaced $\frac{1}{\Delta t} \ln \frac{C_{i}}{C_{f}}$ in (Eq. 3). We did not take any gas samples between 20:00 h and 08:00 h during the experiment, so we calculated the $k$ values for each night of sampling using $C_{f}$ from the previous day as the initial propane concentration and $C_{i}$ from the following day as the final propane concentration. We normalized $k$ values to a $k_{600}$ for propane using the following equation [Jähne et al., 1987]:

$$
\frac{k_{600}}{k_{\text {gas } 2}}=\left(\frac{600}{s c_{\text {gas } 2}}\right)^{n}
$$

where $k_{600}$ is the $k$ for propane at $20^{\circ} \mathrm{C}$ and corresponds to a Schmidt number of 600 , which can be related to the $k$ for any other gas [Raymond et al., 2012]. Sc denotes the Schmidt number for the particular gas of interest, and $n$ is the Schmidt exponent, which varies from 0.5 to -0.67 depending on the boundary conditions. In low-wind environments $\left(<3 \mathrm{~m} \mathrm{~s}^{-1}\right), n$ can be assumed to equal -0.67 [Jähne et al., 1987]. Occasionally, our measurements indicated that propane concentrations increased between sampling times, which likely resulted from spatial heterogeneity in the pond. We only report estimates of $k$ for periods of time where propane concentrations decreased and indicate net propane evasion from the pond.

\subsection{Comparison Across Lake Sizes}

We conducted a meta-analysis to compare our results to other water bodies where $k_{600}$ was directly measured. We identified 18 studies, including ours, representing 67 ponds and lakes ranging in size from $181 \mathrm{~m}^{2}$ to $520 \mathrm{~km}^{2}$ (Dataset $\mathrm{S} 2$ ). With this dataset, we examined the mean and variability of $k_{600}$ across lake sizes and also explored the relationship between surface area and gas exchange rate. 


\subsection{Data Analysis}

To evaluate if $k_{600}$ was influenced by environmental variables, we used linear mixedeffects models with pond as a random effect. Models were created in R ( R Version 3.2.4, R Core Team) using the "Ime4" package [Bates et al., 2014]. Models were constructed using daytime 2-or 3-hour estimates of $k_{600}$, only including estimates where propane concentrations decreased, along with corresponding environmental variables, including time-averaged values of wind speed, light flux, air temperature, water temperature, and the difference between airwater temperature. Air temperature and water temperature were highly correlated and violated assumptions of colinearity; therefore, model selection was done once with air temperature excluded and once with water temperature excluded. Each of the environmental variables were centered and scaled to correct for differences in units by subtracting the mean and dividing by the standard deviation. Models to predict $k_{600}$ were first fit with all environmental variables and then variables were selectively removed one at a time using AICc model selection [Burnham and Anderson, 2002]. Once top predictors were identified, we added back in one variable at a time to ensure we evaluated all possible best models. Top models are reported within two AICc of the best model (lowest AICc). We evaluated mixed model fit by calculating the marginal (variance associated with fixed effects) and conditional $\mathrm{R}^{2}$ (variance associated with fixed and random effects) values [Nakagawa and Schielzeth, 2013] using the "MuMIn" package in R [Barton, 2014]. To assess the relationship between $k_{600}$ and lake size, we used linear models where both lake surface area and $k_{600}$ were natural$\log$ transformed. 


\section{Results}

\subsection{Environmental Variables}

The four study ponds were low-wind environments with average wind speeds ranging between 0.28 and $0.36 \mathrm{~m} \mathrm{~s}^{-1}$ and maximum wind speeds between 3.29 and $4.30 \mathrm{~m} \mathrm{~s}^{-1}$ (Table 1). Total rainfall varied by pond because the injections were done on different days for each pond. Over the duration of the study ( 82 or 83 hours), Brookside experienced the most rainfall $(61.0 \mathrm{~mm})$ and $\mathrm{RH}$ the least $(9.9 \mathrm{~mm})$ (Table 1$)$. Water temperature also varied among the ponds, with $\mathrm{RH}$ being the warmest $\left(22^{\circ} \mathrm{C}\right.$ on average $)$ and Brookside being the coolest $\left(11.1^{\circ} \mathrm{C}\right.$ on average) (Table 1$)$.

\subsection{Estimating Gas Transfer Velocity}

Surface water propane concentrations decreased exponentially over the sampling period in all four ponds (Fig. 1), indicating continuous propane evasion from the ponds to the atmosphere. Initial concentrations of propane measured in the ponds ranged from $89 \mathrm{nmol} \mathrm{L}$ ${ }^{1}$ in $\mathrm{CH}$ to $283 \mathrm{nmol} \mathrm{L}^{1}$ in Westford, and decreased between $51 \%$ and $93 \%$ during the sampling periods (Table 2).

For 12-hour periods, $k_{600}$ averaged between 0.22 and $0.72 \mathrm{~m} \mathrm{day}^{-1}$, with considerable variability within and among ponds (Table 2). For instance, estimates of $k_{600}$ in $\mathrm{CH}$ differed by as much as $1.21 \mathrm{~m} \mathrm{day}^{-1}$ among days. The maximum variability among ponds was $1.23 \mathrm{~m}$ day $^{-1}$, with a minimum of $0.07 \mathrm{~m} \mathrm{day}^{-1}$ in Westford and maximum of $1.30 \mathrm{~m} \mathrm{day}^{-1}$ in $\mathrm{CH}$. There were no significant differences in average $k_{600}$ during the day versus night $(\mathrm{t}$-test, $\mathrm{t}=$ $0.84, \mathrm{df}=15.76, \mathrm{p}=0.42$ ); however average daytime values (ranging: 0.37 to $1.30 \mathrm{~m} \mathrm{day}^{-1}$ ) were slightly higher than average nighttime values (ranging: 0.07 to $1.03 \mathrm{~m} \mathrm{day}^{-1}$ ) in $\mathrm{CH}, \mathrm{RH}$, and Westford, but not Brookside (Table 2). 
When measured across each 2- to 3-hour period for daytime measurements only, the average $k_{600}$ ranged between 0.33 to $1.83 \mathrm{~m} \mathrm{day}^{-1}$, and was also variable within and among ponds (Table 2). For instance, during the three-day study, daytime 2- to 3-hour estimates of $k_{600}$ differed by as much as $3.52 \mathrm{~m} \mathrm{day}^{-1}$ in Brookside. Among ponds, there was a maximum variability of $3.94 \mathrm{~m} \mathrm{day}^{-1}$, with a minimum of $0.01 \mathrm{~m} \mathrm{day}^{-1}$ in $\mathrm{RH}$ and a maximum of $3.95 \mathrm{~m}$ day $^{-1}$ in Brookside.

\subsection{Predictors of Gas Transfer Velocity}

Estimates of $k_{600}$ were negatively correlated with both water and air temperatures, but not significantly correlated with any other environmental variable we measured (Table 3). We identified six mixed-effects models predicting $k_{600}$ (Table 4). Wind and temperature (either water, air, or the difference) were the best predictors (Fig. 2), whereas rain and light were not included in any top model. However, the fixed-effects terms of the model only explained between $11 \%$ and $27 \%$ of total variation, and the null model was two $\mathrm{AIC}_{\mathrm{c}}$ points from the best model. Inter-pond differences explained an additional $12 \%$ to $52 \%$ of the variation, highlighting the importance of differences in $k_{600}$ among ponds.

\subsection{Comparison Across Lake Sizes}

Across the 67 ponds and lakes where $k_{600}$ was directly measured (Dataset S2), we found that $k_{600}$ increased with surface area $\left(\mathrm{R}^{2}=0.29, \mathrm{p}<0.001\right)$, but was highly variable among lake sizes. The measurement method (e.g., gas tracer or floating chamber) did not improve the models of $k_{600}$, but there was a bias towards gas tracer studies in small ponds and chamber studies in large lakes (Dataset S2).

When lakes were grouped into size classes, it appears that $k_{600}$ is fairly constant in lakes smaller than $0.1 \mathrm{~km}^{2}$, and is larger and more variable in larger lakes (Fig. 3). The relative standard deviation in $k_{600}$ increased with lake size class $\left(\mathrm{R}^{2}=0.69, \mathrm{p}=0.02, \mathrm{~F}_{1,5}=\right.$ 11.17), and ranged between 28 and $86 \%$ of the mean. It is also worth noting that the majority 
of the studies $(66 \%)$ were conducted on lakes between 0.01 and $1 \mathrm{~km}^{2}$, meaning that small ponds and large lakes were underrepresented.

\section{Discussion}

We found that the gas transfer velocity, $k_{600}$, in four small, forested ponds was low, variable within and among ponds, and difficult to predict from environmental variables.

When we compared gas exchange rates in our study ponds to larger lakes, we found that $k_{600}$ increased and became more variable with increasing lake size.

\subsection{Estimates of Gas Transfer Velocity}

The average $k_{600}$ when smoothed across 12 -hour periods ranged between 0.22 and $0.72 \mathrm{~m} \mathrm{day}^{-1}$ across the four small ponds (Table 2). These estimates are within the range of average $k_{600}$ values estimated from direct measurements in 30 small $\left(<0.1 \mathrm{~km}^{2}\right)$ water bodies (Fig. 3, Dataset S2). However, we observed high variability both within and among ponds (up to $1.23 \mathrm{~m} \mathrm{day}^{-1}$ among ponds and $1.21 \mathrm{~m} \mathrm{day}^{-1}$ within ponds for 12-hour averages). This sort of variability is large, especially considering that it encompasses nearly the entire range of $k_{600}$ values used across all lake sizes in regional and global carbon models. In these models, the average $k_{600}$ increases with lake size class. Two recent carbon bud gets used $k_{600}$ estimates that ranged from $0.36-0.54$ in the smallest water bodies up to $1.16-1.90 \mathrm{~m} \mathrm{day}^{-1}$ in the largest lakes [Raymond et al., 2013; Holgerson and Raymond, 2016]. Our study combined with our review of other water bodies (Fig. 3) ind icates that $k_{600}$ may be much more variable than previously thought.

We expected that our 12-hour estimates of $k_{600}$ would be greater at night than during the day due to greater convective cooling. As air cools more quickly than water overnight, this stimulates convective mixing that produces turbulence [MacIntyre et al., 2010;

Poindexter and Variano, 2013; Holgerson et al., 2016]. Yet, we only observed a larger nighttime $k_{600}$ in one of the four ponds (Brookside, Table 2). This may be due to our small 
sample size (up to three days and three nights per pond) or because we only sampled during the day (08:00 h to 20:00 h), and therefore did not pick up on short-term fluctuations in gas exchange overnight. As $k_{600}$ may increase significantly for short periods of time at night [Holgerson et al., 2016], future work should investigate overnight gas exchange with a higher temporal resolution.

\subsection{Predictors of Gas Transfer Velocity}

The best predictive models of daytime $k_{600}$ indicate that increased gas exchange occurred with higher wind speeds, lower air temperatures, and when the water was warmer than the air (Table 4, Fig. 2). These predictors were not surprising given that air-water turbulence (which drives $k$ ) is largely influenced by wind speed, solar radiation, and heat flux [Read et al., 2012]. Wind generates turbulence through shear stress and is the primary driver of $k$ in large lakes; however, when wind speeds are low, such as in sheltered and smaller water bodies, convection can be more important for generating turbulence [MacIntyre et al., 2010; Read et al., 2012; Holgerson et al., 2016]. To evaluate convective forces affecting turbulence, the heat bud get must be considered, including turbulent fluxes (latent and sensible heat) and radiative fluxes (short- and long-wave radiation). Because we did not calculate the entire heat budget, we cannot determine the exact mechanisms in which temperature influences $k$. However, we can make several inferences based on our observation that $k$ was higher when air temperatures were lower and as the water became warmer than the air.

Turbulent fluxes can influence gas exchange via both latent (i.e., evaporation) and sensible (e.g., convection) heat fluxes. While wind will increase both latent and sensible heat fluxes in small ponds, temperature influences the sensible heat flux [Woolway et al., 2015]. Indeed, the air-water temperature difference we measured is a good proxy for sensible heat flux [Jonsson et al., 2008; Weyhenmeyer et al., 2017] because when the water is warmer than the air, the boundary layer over the water becomes unstable, which generates turbulence and 
increases gas exchange [MacIntyre et al., 2002]. Small ponds may be more sensitive to the sensible heat flux because they can have higher and more extreme diel changes in water temperature relative to larger lakes [Woolway et al., 2016]. Additionally, long- and shortwave radiation influence heat flux, and outgoing long-wave radiation often contributes the most to surface cooling in small, sheltered ponds [MacIntyre and Melack, 2009]. Therefore, it is likely that warmer water and cooler air temperatures increased daytime $k_{600}$ by altering the heat budget. Future work should measure the full suite of meteorological data necessary to calculate the heat bud get and determine how temperature changes promote increases in $k$. We also found no effect of rain on daytime $k_{600}$, which was surprising as previous studies found that raindrops produce significant turbulence [Ho et al., 1997]. It is likely that we did not experience heavy enough rainfall to greatly alter $k_{600}$. Rainfall $<25 \mathrm{~mm} \mathrm{~h}^{-1}$ is considered light [Ho et al., 1997], and the maximum rainfall event in our study was $1.27 \mathrm{~mm}$ within 15 minutes, likely too low to drive gas exchange in our study ponds.

Even though wind and temperature patterns were the best predictors of daytime $k_{600}$, the fixed effects of the models only explained a small amount $(10-27 \%)$ of overall variation (Table 4). Including pond as a random effect in the model explained an additional $12 \%$ to $52 \%$ of the variation, indicating differences among study sites (Table 4). But considering that most variance came from the random effect of each study site, or was unexplained, it appears that gas exchange cannot be well predicted from these environmental variables, at least not at our coarse resolution or short temporal scale. Our study was limited to three days and three nights per pond based on the rate of propane loss from the ponds. It would be useful to repeat this study multiple times throughout the growing season and sample at a finer resolution, which might better match the scale at which environmental variables are acting. 


\subsection{Comparison Across Lake Sizes}

The variability we observed in $k_{600}$ is similar to or smaller than variability seen in other ponds and lakes around the world (Dataset S2, Fig. 3). Across lake size classes, small ponds and lakes have fairly constant gas exchange rates, with $k_{600}$ increasing and becoming more variable in lakes larger than $0.1 \mathrm{~km}^{2}$ (Fig. 3). Perhaps there is a threshold around 0.1 $\mathrm{km}^{2}$, where larger lakes have enough fetch for wind to significantly increase $k_{600}$. The variability we observed across all lake size classes may help explain why existing predictive models of gas exchange yield significantly different results depending on the model used [Dugan et al., 2016]. Because estimates of $k$ are necessary to calculate ecosystem metabolism and gas emissions across local, regional, and global scales, improving our knowledge of $k$ across space, time, and lake size is a top research priority.

To improve predictive capacity of $k_{600}$, we advise that future gas exchange studies sample during both the day and night and at a finer temporal and spatial scale. One particularly useful tool may be using eddy flux measurements, which directly measures turbulent scalar flows of gas over a given source area and therefore can capture an entire lake’s dynamics [Jonsson et al., 2008; Heiskanen et al., 2014]. Eddy covariance also provides insight into temporal and diel heterogeneity in $k_{600}$ as it can automatically sample over long time-scales [Podgrajsek et al., 2015]. Additionally, it would be interesting to consider how heat flux scales with lake size as small ponds experience greater changes in diurnal temperature and gas exchange appears to be more influenced by convection [Podgrajsek et al., 2015; Woolway et al., 2016]. Future studies also need to increase the representation of different lake sizes, particularly for small ponds and large lakes. Within the small pond size class, ponds can be extremely diverse across the landscape and factors such as depth, mixing, and presence of emergent vegetation may greatly influence $k$ [Poindexter and Variano, 2013; Andersen et al., 2016], which needs further research. With increased 
efforts to improve spatial and temporal resolution across lake sizes, our knowled ge and predictive capacity of $k_{600}$ will improve.

\section{Conclusions}

This study adds small, low-wind ponds to the existing body of research on gas transfer velocities from inland waters. We found that small ponds had lower values of $k_{600}$ relative to larger lakes, but we highlight that $k_{600}$ is variable across space and time for all water bodies, especially large lakes. Because $k_{600}$ was not easily predicted from environmental parameters, and because current predictive models of $k_{600}$ yield significantly different results [Dugan et al., 2016], there is substantial uncertainty when upscaling $k$ to regional or global analyses. Therefore, understanding the drivers and predictors of $k$ is an important research priority, with implications for estimating ecosystem metabolism and global carbon emissions from inland waters.

\section{Acknowledgme nts}

Dataset S1 contains the data on gas exchange from our four study ponds. Dataset S2 contains the $k_{600}$ data from the 67 ponds and lakes used in the meta-analysis. We are grateful for support from the Yale College Science \& Quantitative Reasoning Center, the Yale Environmental Studies Program, Yale University Berkeley College, and Yale Institute for Biospheric Studies. Thank you also to the Yale Myers Forest team for lodging and use of the study ponds. Thank you to D. Vachon for sharing gas exchange data for 8 Canadian lakes. We also thank two anonymous reviewers for their comments to help improve this manuscript. 


\section{Lite rature Cited}

Andersen, M. R., K. Sand-Jensen, R. Iestyn Woolway, and I. D. Jones (2016), Profound daily vertical stratification and mixing in a small, shallow, wind-exposed lake with submerged macrophytes, Aquatic Sciences, 1-12, doi:10.1007/s00027-016-0505-0.

Barton, K. (2014), Package 'MuMIn'. R package version 1.0-7., edited.

Bates, D., M. Maechler, B. Bolker, and S. Walker (2014), lme4: Linear mixed effects models using Eigen and S4. R package version 1.0-7., edited.

Burnham, K. P., and D. R. Anderson (2002), Model selection and multimodel inference: A practical information-theoretic approach, 2nd ed., Springer, New York, New York, USA.

Clark, J. F., P. Schlosser, R. Wanninkhof, H. J. Simpson, W. S. F. Schuster, and D. T. Ho (1995), Gas transfer velocities for SF6 and ${ }^{3} \mathrm{He}$ in a small pond at low wind speeds, Geophysical Research Letters, 22(2), 93-96, doi:10.1029/94g102410.

Cole, J. J., D. L. Bade, D. Bastviken, M. L. Pace, and M. Van de Bogert (2010), Multiple approaches to estimating air-water gas exchange in small lakes, Limnology and Oceanography: Methods, 8, 285-293.

Cole, J. J., and N. F. Caraco (1998), Atmospheric exchange of carbon dioxide in a low-wind oligotrophic lake measured by the addition of $\mathrm{SF}_{6}$, Limnology and Oceanography, 43(4), 647-656.

Devlin, S. P., J. Saarenheimo, J. Syvaranta, and R. I. Jones (2015), Top consumer abundance influences lake methane efflux, Nat Commun, 6, doi:10.1038/ncomms9787.

Downing, J. A. (2010), Emerging global role of small lakes and ponds: little things mean a lot, Limnetica, 29(1), 9-24.

Downing, J. A., Y. T. Prairie, J. J. Cole, C. M. Duarte, L. J. Tranvik, R. G. Striegl, W. H. McDowell, P. Kortelainen, N. F. Caraco, J. M. Melack, and J. J. Middelburg (2006), 
The global abundance and size distribution of lakes, ponds, and impoundments, Limnology and Oceanography, 51(5), 2388-2397.

Dugan, H., R. I. Woolway, A. Santoso, J. Corman, A. Jaimes, E. Nodine, V. Patil, J. Zwart, J. Brentrup, and A. Hetherington (2016), Consequences of gas flux model choice on the interpretation of metabolic balance across 15 lakes, Inland Waters, 6(4), 581-592.

Frost, T., and R. C. Upstill-Goddard (2002), Meteorological controls of gas exchange at a small English lake, Limnology and Oceanography, 47(4), 1165-1174, doi:10.4319/lo.2002.47.4.1165.

Heiskanen, J. J., I. Mammarella, S. Haapanala, J. Pumpanen, T. Vesala, S. MacIntyre, and A. Ojala (2014), Effects of cooling and internal wave motions on gas transfer coefficients in a boreal lake, Tellus. Series B: Chemical and Physical Meteorology, $66,22827$.

Ho, D. T., L. F. Bliven, R. I. K. Wanninkhof, and P. Schlosser (1997), The effect of rain on air-water gas exchange, Tellus B, 49(2), 149-158, doi:10.1034/j.16000889.49.issue2.3.x.

Holgerson, M. A., and P. A. Raymond (2016), Large contribution to inland water CO2 and $\mathrm{CH} 4$ emis sions from very small ponds, Nature Geoscience, 9, 222-226, doi:10.1038/ngeo2654.

Holgerson, M. A., C. J. Zappa, and P. A. Raymond (2016), Substantial overnight reaeration by convective cooling discovered in pond ecosystems, Geophysical Research Letters, $43,8044-8051$.

Jähne, B., G. Heinz, and W. Dietrich (1987), Measurement of the diffusion coefficients of sparingly soluble gases in water, Journal of Geophysical Research, 92(C10), 1076710776. 
Jin, H.-S., D. White, J. Ramsey, and G. Kipphut (2012), Mixed tracer injection method to measure reaeration coefficients in small streams, Water, Air, \& Soil Pollution, 223(8), 5297-5306, doi:10.1007/s11270-012-1280-8.

Jonsson, A, J. Åberg, A. Lindroth, and M. Jansson (2008), Gas transfer rate and CO2 flux between an unproductive lake and the atmosphere in northern Sweden, Journal of Geophysical Research: Biogeosciences, 113(G4), G04006, doi:10.1029/2008JG000688.

MacIntyre, S., A. Jonsson, M. Jansson, J. Aberg, D. E. Turney, and S. D. Miller (2010), Buoyancy flux, turbulence, and the gas transfer coefficient in a stratified lake, Geophysical Research Letters, 37(24), L24604, doi:10.1029/2010g1044164.

MacIntyre, S., and J. M. Melack (2009), Mixing dynamics in lakes across climatic zones, Encyclopedia of Inland Waters, 603-612.

MacIntyre, S., J. R. Romero, and G. W. Kling (2002), Spatial-temporal variability in surface layer deepening and lateral advection in an embayment of Lake Victoria, East Africa, Limnology and Oceanography, 47(3), 656-671, doi:10.2307/3069155.

MacIntyre, S., R. Wanninkhof, and J. P. Chanton (1995), Trace gas exchange across the airwater interface in freshwater and coastal marine environments, in Biogenic trace gases: Measuring emissions from soil and water, edited by P. A. Matson and R. C. Harriss, Wiley-Blackwell, Cambridge, Massachusetts, USA.

Matthews, C. J. D., V. L. St.Louis, and R. H. Hesslein (2003), Comparison of three techniques used to measure diffusive gas exchange from sheltered aquatic surfaces, Environmental Science \& Technology, 37(4), 772-780, doi:10.1021/es0205838.

Melack, J. M., and T. R. Fisher (1983), Diel oxygen variations and their ecological implications in Amazon floodplain lakes, Archiv für Hydrobiologie, 98(4), 422-442. 
Mohebbi, V., A. Naderifar, R. M. Behbahani, and M. Moshfeghian (2012), Determination of Henry's law constant of light hydrocarbon gases at low temperatures, The Journal of Chemical Thermodynamics, 51, 8-11, doi:10.1016/j.jct.2012.02.014.

Nakagawa, S., and H. Schielzeth (2013), A general and simple method for obtaining R2 from generalized linear mixed-effects models, Methods in Ecology and Evolution, 4(2), 133-142, doi:10.1111/j.2041-210x.2012.00261.x.

Podgrajsek, E., E. Sahlée, and A. Rutgersson (2015), Diel cycle of lake-air CO2 flux from a shallow lake and the impact of waterside convection on the transfer velocity, Journal of Geophysical Research: Biogeosciences, 120(1), 2014JG002781, doi:10.1002/2014JG002781.

Poindexter, C. M., and E. A. Variano (2013), Gas exchange in wetlands with emergent vegetation: The effects of wind and thermal convection at the air-water interface, Journal of Geophysical Research: Biogeosciences, 118(3), 1297-1306, doi:10.1002/jgrg.20099.

Raymond, P. A., N. F. Caraco, and J. J. Cole (1997), Carbon dioxide concentration and atmospheric flux in the Hudson River, Estuaries, 20(2), 381-390, doi:10.2307/1352351

Raymond, P. A., et al. (2013), Global carbon dioxide emissions from inland waters, Nature, 503(7476), 355-359, doi:10.1038/nature12760.

Raymond, P. A., C. J. Zappa, D. Butman, T. L. Bott, J. Potter, P. Mulholland, A. E. Laursen, W. H. McDowell, and D. Newbold (2012), Scaling the gas transfer velocity and hydraulic geometry in streams and small rivers, Limnology and Oceanography: Fluids and Environments, 2(1), 41-53, doi:10.1215/21573689-1597669. 
Read, J. S., et al. (2012), Lake-size dependency of wind shear and convection as controls on gas exchange, Geophysical Research Letters, 39(9), L09405, doi:10.1029/2012g1051886.

Sander, R. (2015), Compilation of Henry's law constants (version 4.0) for water as solvent, Atmospheric Chemistry \& Physics, 15(8).

Schilder, J., D. Bastviken, M. van Hardenbroek, P. Kankaala, P. Rinta, T. Stötter, and O. Heiri (2013), Spatial heterogeneity and lake morphology affect diffusive greenhouse gas emission estimates of lakes, Geophysical Research Letters, 2013GL057669, doi:10.1002/2013g1057669.

Schindler, D. E., S. R. Carpenter, J. J. Cole, J. F. Kitchell, and M. L. Pace (1997), Influence of food web structure on carbon exchange between lakes and the atmosphere, Science, 277(5323), 248-251.

Seekell, D. A., J. A. Carr, C. Gudasz, and J. Karlsson (2014), Upscaling carbon dioxide emissions from lakes, Geophysical Research Letters, 41(21), 2014GL061824, doi:10.1002/2014GL061824.

Soloviev, A., M. Donelan, H. Graber, B. Haus, and P. Schlüssel (2007), An approach to estimation of near-surface turbulence and $\mathrm{CO} 2$ transfer velocity from remote sensing data, Journal of Marine Systems, 66(1-4), 182-194, doi:http://dx.doi.org/10.1016/i.jmarsys.2006.03.023.

Vachon, D., and Y. T. Prairie (2013), The ecosystem size and shape dependence of gas transfer velocity versus wind speed relationships in lakes, Canadian Journal of Fisheries and Aquatic Sciences, 70, 1757-1764, doi:10.1139/cjfas-2013-0241.

Vachon, D., Y. T. Prairie, and J. J. Cole (2010), The relationship between near-surface turbulence and gas transfer velocity in freshwater systems and its implications for 
floating chamber measurements of gas exchange, Limnology and Oceanography, 55(4), 1723-1732, doi:10.4319/lo.2010.55.4.1723.

Verpoorter, C., T. Kutser, D. A. Seekell, and L. J. Tranvik (2014), A global inventory of lakes based on high-resolution satellite imagery, Geophysical Research Letters, 41, 6396-6402, doi:10.1002/2014g1060641.

Wanninkhof, R. (1992), Relationship between wind speed and gas exchange over the ocean, Journal of Geophysical Research, 97, 7373-7382.

Wanninkhof, R., J. R. Ledwell, and W. S. Broecker (1985), Gas exchange-wind speed relation measured with sulfur hexafluoride on a lake, Science, 227(4691), 1224-1226, doi:10.1126/science.227.4691.1224.

Wanninkhof, R., J. R. Ledwell, W. S. Broecker, and M. Hamilton (1987), Gas exchange on Mono Lake and Crowley Lake, California, Journal of Geophysical Research: Oceans, 92(C13), 14567-14580, doi:10.1029/JC092iC13p14567.

Weyhenmeyer, G. A., et al. (2017), Citizen science shows systematic changes in the temperature difference between air and inland waters with global warming, Scientific Reports, 7, 43890, doi:10.1038/srep43890.

Winslow, L. A., J. Zwart, R. D. Batt, H. Dugan, R. I. Woolway, J. Corman, P. C. Hanson, and J. S. Read (2016), LakeMetabolizer: an R package for estimating lake metabolism from free-water oxygen using diverse statistical models, Inland Waters, 6(622-636). Woolway, R. I., I. D. Jones, D. P. Hamilton, S. C. Maberly, K. Muraoka, J. S. Read, R. L. Smyth, and L. A. Winslow (2015), Automated calculation of surface energy fluxes with high-frequency lake buoy data, Environmental Modelling \& Software, 70, 191198, doi:http://dx.doi.org/10.1016/j.envsoft.2015.04.013.

Woolway, R. I., et al. (2016), Diel surface temperature range scales with lake size, PLOS ONE, 11(3), e0152466, doi:10.1371/journal.pone.0152466. 
Zappa, C. J., W. R. McGillis, P. A. Raymond, J. B. Edson, E. J. Hintsa, H. J. Zemmelink, J. W. H. Dacey, and D. T. Ho (2007), Environmental turbulent mixing controls on airwater gas exchange in marine and aquatic systems, Geophysical Research Letters, 34(10), L10601, doi:10.1029/2006g1028790.

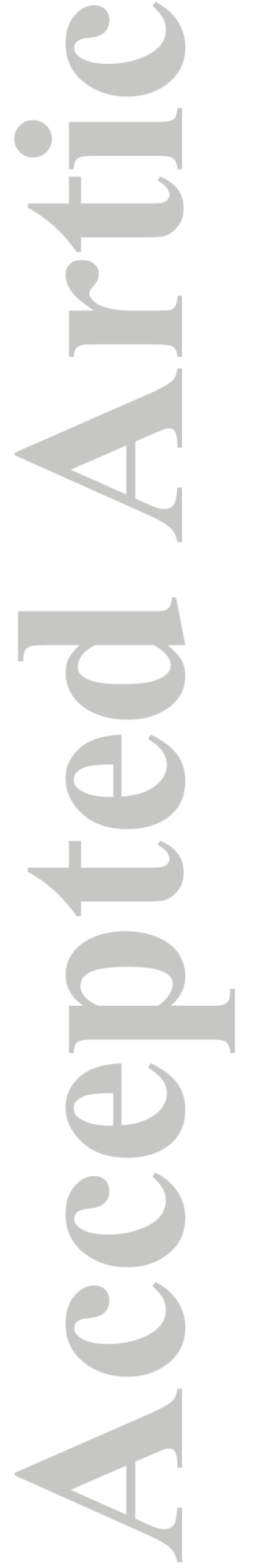




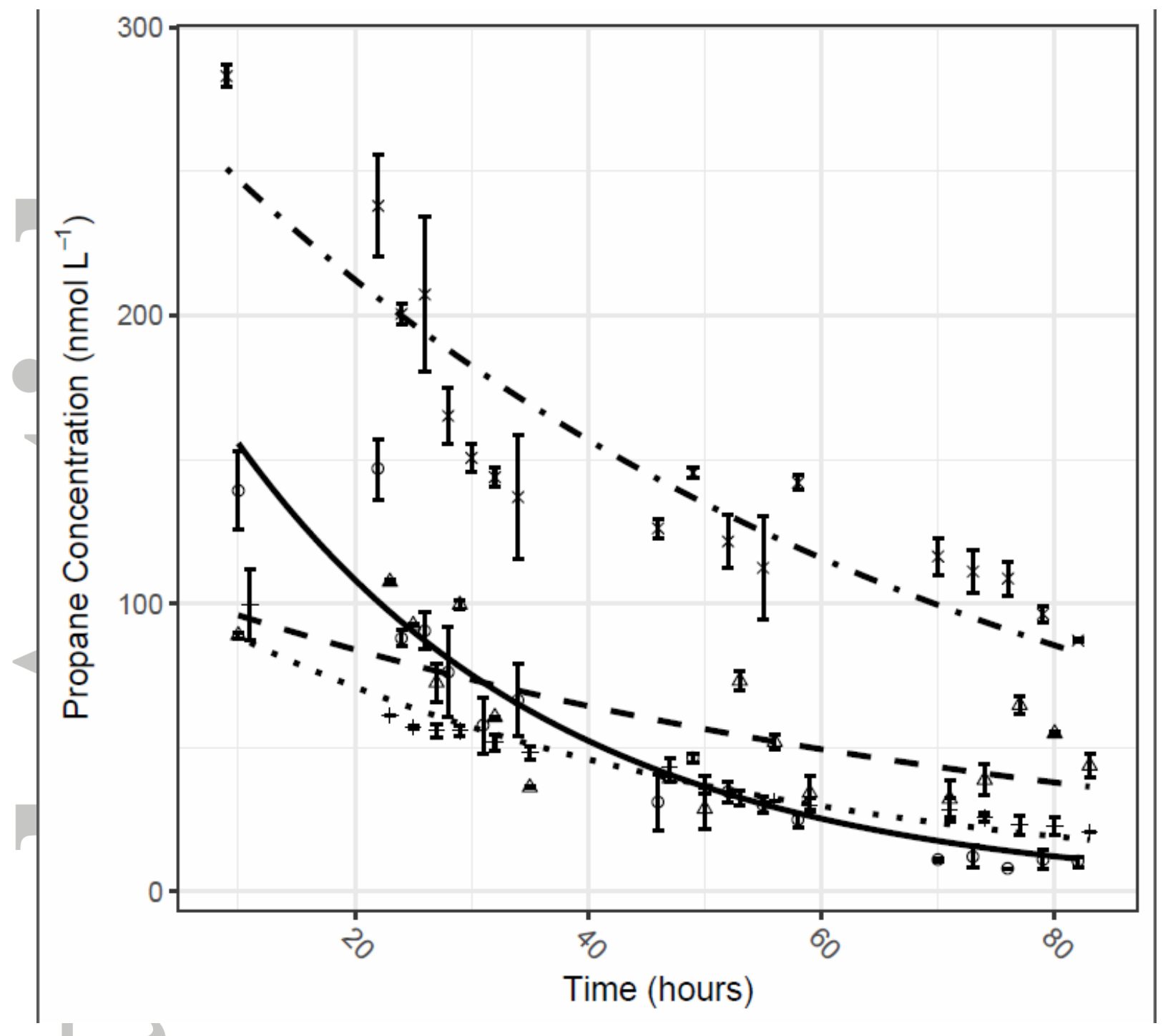

Figure 1. Propane concentrations $\pm \mathrm{SE}$ across time since the propane addition in the four study ponds (Brookside: circles with solid line; $\mathrm{CH}$ : triangles with dashed line; $\mathrm{RH}$ : cross with dotted line; Westford: $\mathrm{x}$ with dashed-dotted line). For each pond, a generalized linear model (GLM) was fit with the log-link function, and quasi- $\mathrm{R}^{2}$ values were calculated (Brookside $\mathrm{R}^{2}=0.90 ; \mathrm{CH} \mathrm{R}^{2}=0.45 ; \mathrm{RH} \mathrm{R}^{2}=0.94$; Westford $\mathrm{R}^{2}=0.82$ ). 


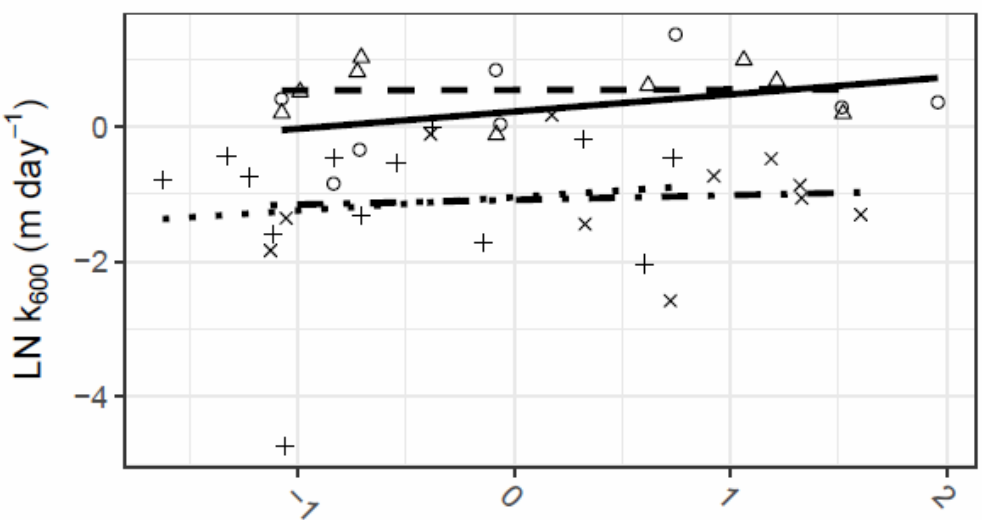

Avg. Wind Speed (scaled)

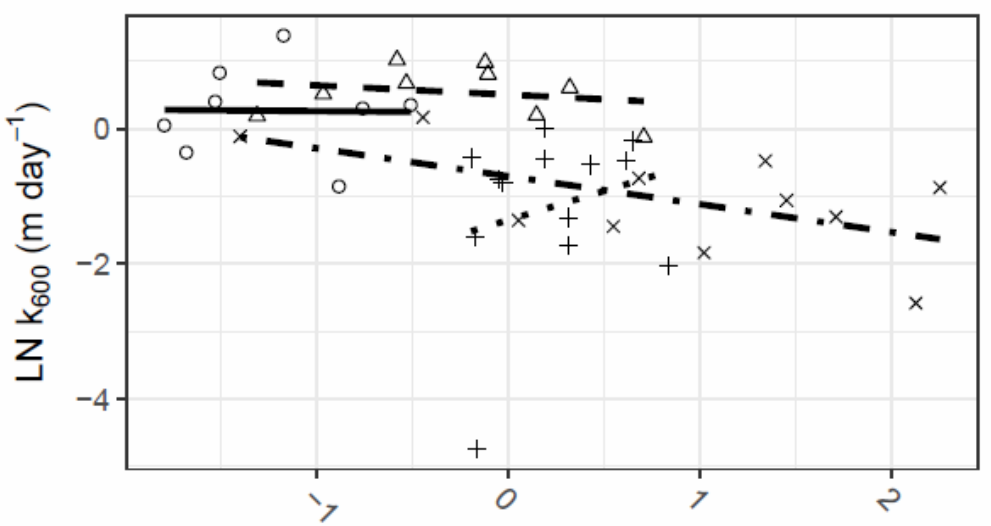

Air temp. (scaled)

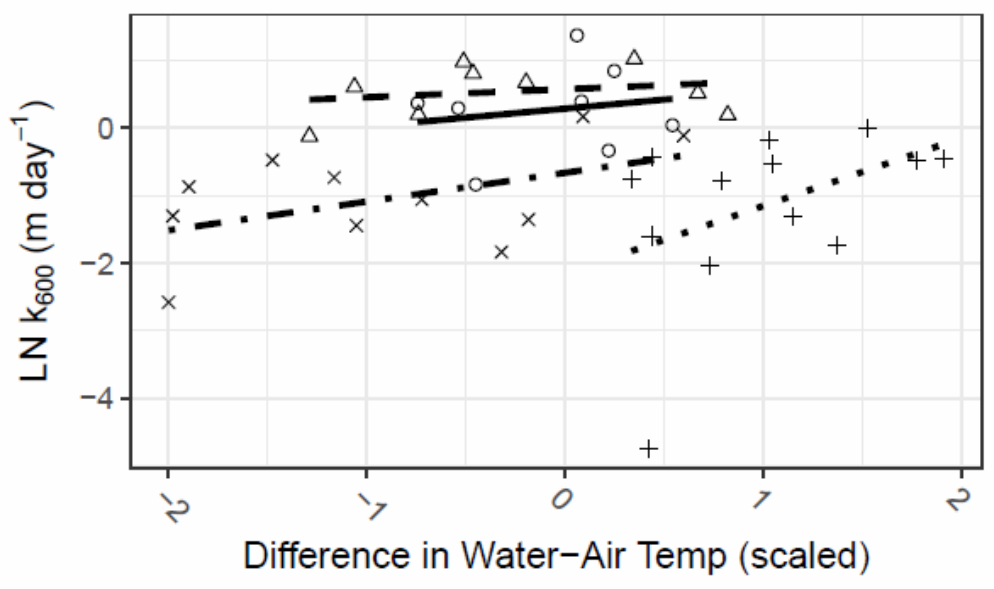

Figure 2. Relationship between $k_{600}$ and (A) average wind speed, (B) air temperature, and (C) difference in water-air temperature across two- or three-hour periods during daytime hours. Sampling periods where propane concentrations increased were excluded from analysis. Data is scaled by subtracting the mean and dividing by the standard deviation of the raw data (see text). Brookside: circles with solid line; $\mathrm{CH}$ : triangles with dashed line; $\mathrm{RH}$ : cross with dotted line; Westford: $\mathrm{x}$ with dashed-dotted line. 


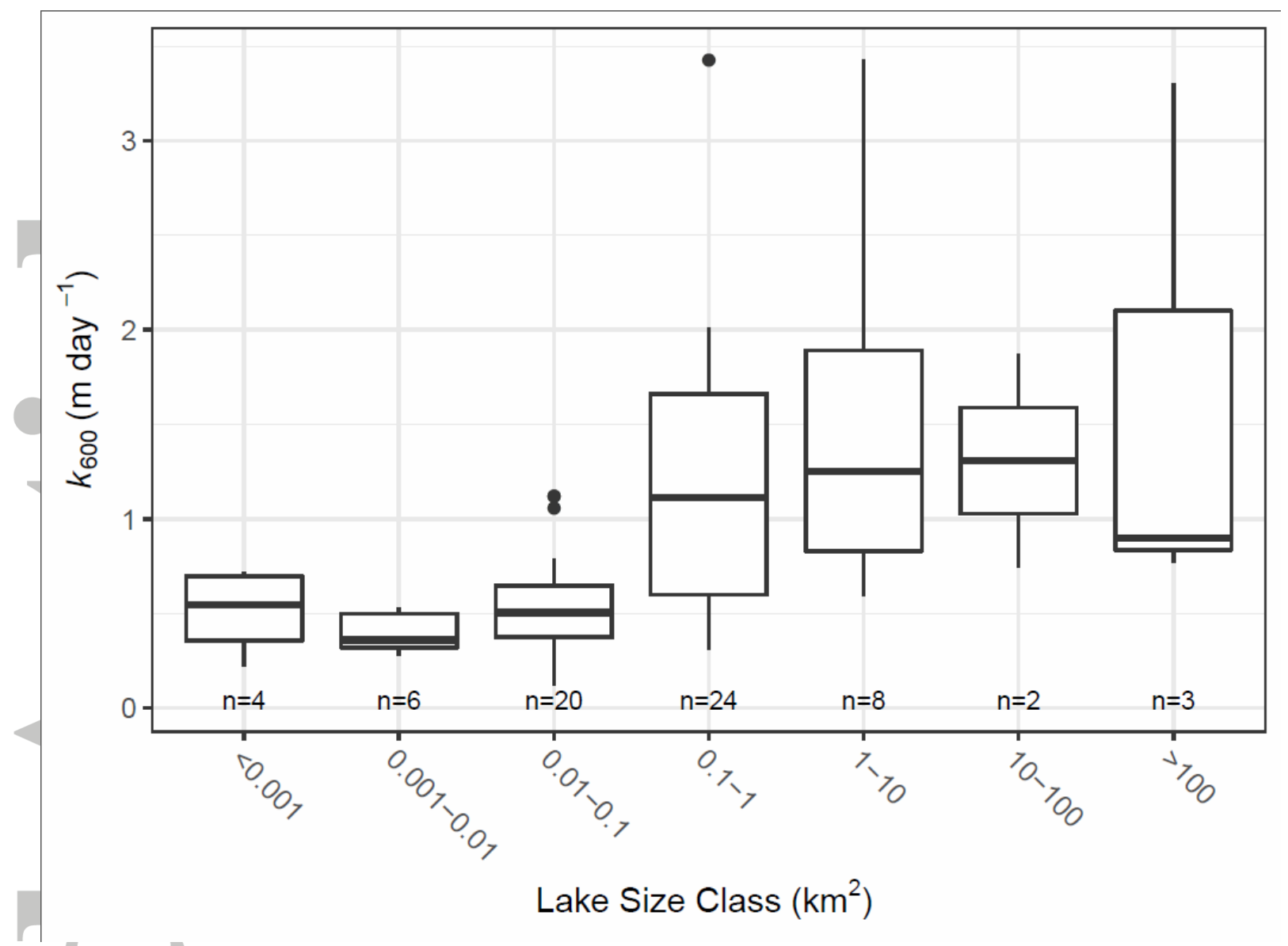

Figure 3. Estimates of $k_{600}$ for 67 ponds and lakes across a size gradient where $k_{600}$ was directly measured via floating chambers or gas tracers. The box represents the interquartile range and median, whereas the whiskers extend 1.5 times the interquartile range. 
Table 1. Environmental characteristics of the four study ponds. Temperature and wind speed are averaged across the entire study period ( 82 or 83 hours), while rain is cumulative.

\begin{tabular}{lcccc}
\hline & Brookside & $\mathrm{CH}$ & $\mathrm{RH}$ & Westford \\
\hline Date of propane addition & 11 June & 18 June & 26 June & 28 May \\
Surface area $\left(\mathrm{m}^{2}\right)$ & 225 & 181 & 197 & 213 \\
Average depth $(\mathrm{cm})$ & 46 & 48 & 56 & 31 \\
Maximum depth $(\mathrm{cm})$ & 72 & 96 & 99 & 74 \\
Average water temperature $\left({ }^{\circ} \mathrm{C}\right)$ & 11.1 & 13.8 & 22.0 & 15.7 \\
Average wind speed $\left(\mathrm{m} \mathrm{s}^{-1}\right)$ & 0.33 & 0.35 & 0.28 & 0.35 \\
Maximum wind speed $\left(\mathrm{m} \mathrm{s}^{-1}\right)$ & 4.30 & 3.32 & 3.53 & 3.29 \\
Total rain $(\mathrm{mm})$ & 61.0 & 14.7 & 9.9 & 20.6 \\
\hline
\end{tabular}


Table 2. Summary of pond measurements during the propane addition.

\begin{tabular}{|c|c|c|c|c|}
\hline & Brookside & $\mathrm{CH}$ & RH & Westford \\
\hline Initial concentration $\left(\mathrm{nmol} \mathrm{L}^{-1}\right)^{\mathrm{A}}$ & 139.3 & 89.0 & 99.6 & 283.1 \\
\hline Final concentration $\left(\mathrm{nmol} \mathrm{L}{ }^{-1}\right)^{\mathrm{B}}$ & 10.3 & 43.8 & 20.7 & 87.2 \\
\hline $\begin{array}{l}k_{600}, \text { averaged across day and } \\
\text { night } 12 \text {-hour periods }\left(\mathrm{m} \mathrm{d}^{-1}\right) \mathrm{C}\end{array}$ & $\begin{array}{c}0.72 \\
(0.19)\end{array}$ & $\begin{array}{c}0.69 \\
(0.61)\end{array}$ & $\begin{array}{c}0.40 \\
(0.10)\end{array}$ & $\begin{array}{c}0.22 \\
(0.07)\end{array}$ \\
\hline $\begin{array}{l}\text { Daytime } k_{600}, \text { across } 12 \text {-hour } \\
\text { periods }\left(\mathrm{m} \mathrm{d}^{-1}\right){ }^{\mathrm{D}}\end{array}$ & 0.51 & 1.30 & 0.46 & 0.37 \\
\hline $\begin{array}{l}\text { Nighttime } k_{600} \text {, across } 12 \text {-hour } \\
\text { periods }\left(\mathrm{m} \mathrm{d}^{-1}\right)\end{array}$ & 1.03 & 0.08 & 0.34 & 0.13 \\
\hline $\begin{array}{l}\text { Daytime } k_{600} \text { day, across } 2-\text { or } 3- \\
\text { hour periods }\left(\mathrm{m} \mathrm{d}^{-1}\right)^{\mathrm{F}}( \pm \mathrm{SE})\end{array}$ & $\begin{array}{c}1.59 \\
(0.39)\end{array}$ & $\begin{array}{c}1.83 \\
(0.22)\end{array}$ & $\begin{array}{c}0.46 \\
(0.08)\end{array}$ & $\begin{array}{c}0.33 \\
(0.10)\end{array}$ \\
\hline
\end{tabular}

${ }^{\text {A }}$ Initial concentration was taken 9 to 11 hours after propane addition to permit for mixing.

${ }^{\mathrm{B}}$ Final concentration was taken at 19:00 or 20:00 just prior to sunset, which was 82 to 83 hours after propane addition.

${ }^{\mathrm{C}} k_{600}$ average was calculated across all 12 -hour periods when propane concentrations decreased (Brookside n=5, CH n=2, RH n=6, Westford n=5).

${ }^{\mathrm{D}}$ Daytime $k_{600}$ was calculated from the slope of daytime propane loss and averaged across sampling days where propane measurements declined (Brookside $n=3, R^{2}$ range $=0.03-0.74$; $\mathrm{CH} n=1, \mathrm{R}^{2}=0.78 ; \mathrm{RH} n=3, \mathrm{R}^{2}$ range=0.90-0.97; Westford $\mathrm{n}=2, \mathrm{R}^{2}$ range=0.93-0.94).

${ }^{\mathrm{E}}$ Nighttime $k_{600}$ was calculated from difference in propane between the last measurement of the day and the next morning (08:00), and then averaged across sampling nights when propane measurements declined (Brookside $n=2, \mathrm{CH} \mathrm{n}=1, \mathrm{RH} n=3$, Westford $n=3$ ).

Daytime $k_{600}$ averaged from 2- or 3-hour sampling periods, and only estimated when propane concentrations declined (Brookside $n=8, \mathrm{CH} n=9, \mathrm{RH} n=13$, Westford $n=11$ ). 
Table 3. Pearson correlation coefficients between daytime $k_{600}$ and environmental variables ( $\mathrm{n}=41$ for all variables).

\begin{tabular}{llllllll}
\hline & Water temp. & Air temp. & Rain & Light & Wind & $\begin{array}{l}\text { Air-water } \\
\text { temp. diff. }\end{array}$ & $k_{600}(\ln )$ \\
\hline Water temp. & 1 & $0.54^{* *}$ & -0.29 & 0.26 & -0.14 & $0.51^{* *}$ & $-0.44^{* *}$ \\
Air temp. & & 1 & $-0.45^{* *}$ & $0.62^{* *}$ & 0.29 & $-0.43^{* *}$ & $-0.47^{* *}$ \\
Rain & & & 1 & -0.19 & -0.17 & 0.12 & 0.06 \\
Light & & & & 1 & $0.48^{* *}$ & $-0.33^{*}$ & -0.21 \\
Wind & & & & 1 & -0.44 & 0.18 \\
Air-water temp. diff. & & & & & 1 & 0.04 \\
$k_{600}(\ln )$ & & & & & & 1 \\
\hline
\end{tabular}

Significance of the coefficient denoted by asterisks: $* \mathrm{p} \leq 0.05, * * \mathrm{p} \leq 0.01$

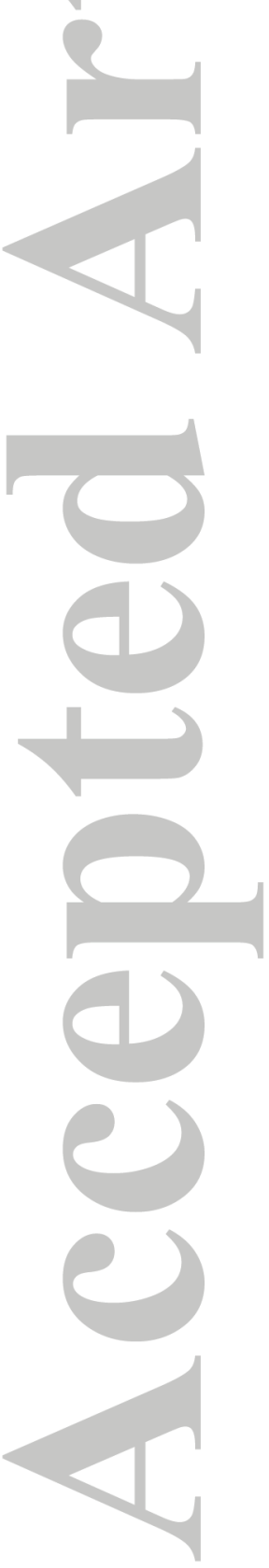


Table 4. Linear-mixed effects models for predicting daytime $k_{600}$. Daytime $k_{600}$ was estimated for each period between propane sampling (2-3 hours apart) and only include periods when propane concentrations declined. Each model includes pond as a random effect. Models within 2 AICc units of the best model are included. Estimates include SE.

\begin{tabular}{|c|c|c|c|c|c|c|c|c|}
\hline $\begin{array}{ll}\text { Model } & \mathrm{k}\end{array}$ & $\overline{\mathrm{AIC}_{\mathrm{c}}}$ & $\overline{\Delta \mathrm{AIC}_{\mathrm{c}}}$ & $\begin{array}{l}\mathrm{R}^{2} \\
\text { marg. }\end{array}$ & $\mathrm{R}^{2}$ cond. & $\begin{array}{l}\text { Intercept } \\
\text { Estimate }\end{array}$ & $\begin{array}{l}\text { Wind } \\
\text { Estimate }\end{array}$ & $\begin{array}{l}\text { Water-air } \\
\text { Estimate }\end{array}$ & $\begin{array}{l}\text { Additional } \\
\text { Covariate } \\
\text { Estimate } \\
\end{array}$ \\
\hline Wind + air temp. & 119.2 & 0 & 0.24 & 0.38 & $\begin{array}{l}-0.44 \\
(0.24)\end{array}$ & $\begin{array}{l}0.32 \\
(0.15)\end{array}$ & & $\begin{array}{l}-0.52 \\
(0.18)\end{array}$ \\
\hline $\begin{array}{l}\text { Water-air temp. } \\
\text { difference }\end{array}$ & 120.1 & 0.8 & 0.10 & 0.54 & $\begin{array}{l}-0.34 \\
(0.43)\end{array}$ & & $\begin{array}{l}0.38 \\
(0.19)\end{array}$ & \\
\hline $\begin{array}{l}\text { Wind + water-air } \\
\text { temp. difference }\end{array}$ & 120.3 & 1.1 & 0.11 & 0.55 & $\begin{array}{l}-0.35 \\
(0.42)\end{array}$ & $\begin{array}{l}0.22 \\
(0.14)\end{array}$ & $\begin{array}{l}0.46 \\
(0.19)\end{array}$ & \\
\hline Air temp. & 120.5 & 1.2 & 0.11 & 0.34 & $\begin{array}{l}-0.41 \\
(0.29)\end{array}$ & & & $\begin{array}{l}-0.35 \\
(0.18)\end{array}$ \\
\hline $\begin{array}{l}\text { Water-air temp. } \\
\text { difference + light }\end{array}$ & 120.7 & 1.4 & 0.11 & 0.63 & $\begin{array}{l}-0.32 \\
(0.49)\end{array}$ & & $\begin{array}{l}0.46 \\
(0.19)\end{array}$ & $\begin{array}{l}0.25 \\
(0.17)\end{array}$ \\
\hline $\begin{array}{l}\text { Wind + water-air } \\
\text { temp difference }+ \\
\text { water temperature }\end{array}$ & 120.8 & 1.6 & 0.27 & 0.39 & $\begin{array}{l}-0.44 \\
(0.23)\end{array}$ & $\begin{array}{l}0.34 \\
(0.15)\end{array}$ & $\begin{array}{l}0.55 \\
(0.20)\end{array}$ & $\begin{array}{l}-0.57 \\
(0.22)\end{array}$ \\
\hline Null $\quad 0$ & 121.2 & 2 & 0 & 0.39 & $\begin{array}{l}-0.37 \\
(0.38)\end{array}$ & & & \\
\hline
\end{tabular}

$\mathrm{R}^{2}$ marginal accounts for fixed effects

$\mathrm{R}^{2}$ conditional accounts for fixed and random effects 